Social Work/Maatskaplike Werk Vol 50 No 3; (3)

http://socialwork.journals.ac.za/pub. http://dx.doi.org/10.15270/50-2-404

\title{
THE INFLUENCE OF BINGE DRINKING ON SOCIAL SUPPORT NETWORKS
}

Marilyn Setlalentoa, North-West University, Mafikeng Campus, South Africa, Elma Ryke, Herman Strydom, North-West University, Potchefstroom Campus, Potchefstroom, South Africa

Abstract

People and environments influence each other, negatively and positively. The abuse of alcohol affects any network negatively. The concepts "social support" and "networks" are described to demonstrate the interdependence and interrelatedness of systems and how they are affected by binge drinking. The emphasis is on the type of support, recipient perception, reciprocal support and behaviour of providers. Social support is important for the optimal functioning of social support networks and binge drinking could inhibit provision of such support and lead to social dysfunctioning. In order to address the problem of alcohol abuse an appropriate, relevant, holistic multidisciplinary intervention strategy is needed. 


\section{THE INFLUENCE OF BINGE DRINKING ON SOCIAL SUPPORT NETWORKS}

\section{Marilyn Setlalentoa, Elma Ryke, Herman Strydom}

\section{INTRODUCTION}

The hazardous and harmful use of alcohol is a major global contributory factor to death, disease and injury (World Health Organisation [WHO], 2011:9). These effects are likely to affect the individuals, families and other support networks negatively because of their interdependence and interrelatedness. Binge drinking is "a single drinking session intended to or actually leading to intoxication and it is risky. It is self-destructive and unrestrained drinking bouts can last for at least a couple of days" (Plant \& Plant, 2006:ix). The drinker would not work, fail to perform his/her roles, ignore responsibilities, squander money and engage in harmful behaviours such as fighting or even risky sex. These behaviours affect other sub-systems negatively. The negative effects could be family disputes, neglect, abuse, or divorce to mention a few. Mokdad, Brewer and Warner (2007:303) and Norman, Armitage and Quickley (2007:1753) support the view that binge drinking is associated with a myriad of health and social problems and negative consequences, including unintentional injuries, interpersonal violence, alcohol poisoning, sexually transmitted diseases, unintended pregnancy and sudden infant death syndrome.

The misuse or abuse of alcohol is one of the serious social, economic and health problems faced by many countries. South Africa is no exception and the concern about alcohol abuse has been highlighted by many authors and politicians. Skweyiya, in his media statement on substance abuse (2005), says that the high rate of binge drinking is a cause for concern, given the significant association between alcohol abuse, academic failure and high-risk sexual behaviour. The consumption of a large amount of alcohol places the drinker at increased risk of experiencing alcohol-related problems. The social support networks are also affected by alcohol abuse because of support is not, or cannot be, provided.

According to Tracy and Whittaker (1990:462), "a social network is a set of relationships that provide nurturance and reinforcement for coping with life on a daily basis. It is a complex and multi-dimensional construct, consisting of social network resources, types of supportive exchanges, perceptions of support availability, and skills in accessing and maintaining supportive relationships". They further acknowledge that not all networks are socially supportive, nor do they always reinforce positive social behaviours. This could be attributed to many negative factors such as failure to perform roles as a result of alcohol abuse. Personal contacts or relationships have a particular role to play in one's life, such as the provision of emotional, instrumental or financial support. It is therefore critical that different systems, including social work, should focus on holistic and comprehensive intervention strategies. 


\section{PROBLEM STATEMENT}

Parry, Plüddeman, Steyn, Bradshaw, Norman and Laubsher (2005:91) state that alcohol has played a major role in the lives of many South Africans in causing family disruption and a host of individual and societal problems that are harmful for the individual drinker, his or her immediate environment and society as a whole. This abuse impairs the individual's functioning in various social roles, such as father, mother, spouse, community member or employee.

Members of a social support network such as a family are placed at increased risk of experiencing various detrimental effects that are caused by abuse of alcohol, such as death of a breadwinner, failure to fulfil social role obligations or incidences of violence in the family that could lead to premature death. A parent or spouse might spend more time with drinking networks rather than with the family. Alcohol abuse also costs money and can impact upon limited resources, particularly of a poor family. The family could also experience mental health problems as a result of problems arising from alcohol abuse (WHO, 2004:59-60). The economic consequences could further be linked to low productivity, absenteeism and job loss. For instance, heavy drinking could lead to termination of employment and being unemployed may result in increased drinking, which may in turn lead to a more serious drinking problem and financial problems for the family system, especially those for living in poverty. All these conditions create a situation where provision of social support could be compromised.

Three perspectives are discussed to provide a theoretical basis that supports the argument that social support networks are adversely affected by binge drinking. The ecosystems' perspective is used to elucidate the interconnectedness and interrelatedness of the social support networks of binge drinkers. Role theory clarifies the importance of role performance and how role obligations contribute to the balance of a system and how failure to perform roles destabilises a system or network. It is also imperative to consider how socially constructed views could contribute to abuse of alcohol and in turn affect social networks. It would be helpful to develop a comprehensive picture of the situation that would contribute to the development of an intervention strategy.

It is against this background that a literature review on social support, social support networks and social network analysis is done to understand the concepts and the link between social support and binge drinking. This would assist in describing how the social support networks are affected by binge drinking. Such an exploration would contribute to the five-year multidisciplinary alcohol study of the Prospective Urban and Rural Epidemiology (PURE) study that aims to acquire a better understanding of the alcohol consumption patterns as well as the causes and consequences of binge drinking amongst South Africans. This understanding would contribute to the development of a relevant, integrated and coherent strategy to address alcohol abuse and misuse in South Africa.

\section{THEORETICAL PERSPECTIVES}

The ecosystems perspective, role theory and constructivism perspective as a postmodern perspective are explained to unpack the relation between people and 
environments and how they influence and affect one another, the roles performed by members of networks and how failure to perform could affect others and understanding of peoples' reality and how it affects others.

\section{Ecosystems perspective}

The ecosystems perspective is a conceptual scheme consisting of layers and sets of interrelated concepts that can explain human behaviour in the context of the environment (Compton, Galaway \& Cournoyer 2005:38; Pillari \& Newsome, 1998:6). Compton et al. (2005:23) and Poulin (2005:27) are of the view that the person-insituation is a whole in which the person and the situation are both cause and effect in a complex set of relationships. In order to understand the dynamic interactions and transactions, the whole system should be considered. The rationale is that systems are interrelated and interdependent. Hull and Mather (2006:12) support this view with the family-in-environment practice approach in that one cannot adequately assess a family without recognising the multiple influences that affect the lives of family members of any family system.

McGregor et al. (in Becker \& Vanclay, 2003:108) refer to the ecological model of wellbeing that assumes that a healthy ecological system is the foundation for a functional economy and social system that can sustain a high quality of life for its residents. They argue that different ecological models explain the effects of environment on personal identity and predispositions, family structure and roles, and communal networks and patterns. Seed (1990:11) argues that the idea of "system" overlaps with the idea of "network". A system is often represented as a network, such as client or action systems. He further states that social network analysis gives a landscape to these systems.

Compton et al. (2005:7) and Pillari and Newsome (1998:7) state that a focus on a person-in-environment assists people to address problems, needs and aspirations that are associated with obstacles that impede successful accomplishment of transitional and environmental tasks. The transactions between people and environments are viewed as being in a constant state of reciprocity, each affecting the other. They further state that people experience problems when there is a poor fit between their needs and wants and the resources available in their environments such as family, community or society. Binge drinking, with its devastating effects, could impede successful accomplishment of transitional and environmental tasks.

Ecological theory is selected as a cornerstone of the strengths model (Long, Tice \& Morrison, 2006:34). The rationale is that the social environment component of ecological theory involves the conditions and interpersonal interactions that permit people to survive and thrive in hostile circumstances. The concept of social environment includes people's homes, communities and financial and/or other resources, as well as laws and expectations that govern social behaviours. A binge drinker is aligned with these as he is part of a home and a community, and could be a provider of financial and/or other resources. Binge drinking is seen as a behaviour that transgresses alcohol intake limits as set out by law as well as the expectations of a particular community. 
Ecological theory also supports the value of transactions as a forum to build on the strengths of informal and formal support systems.

The social support networks are seen as an important part of persons' environment that has an influence on their growth and development. In terms of the ecological perspective, a person who is a binge drinker needs to be understood in the context of his environment. Those who are part of his networks are also affected by his binge drinking because they are, as subsystems of a system, affecting each other. As a unit, the social support network could become unbalanced because of binge drinking that is out of control.

\section{Role theory}

A role refers to the expected behaviour for a person occupying a particular social status or position (Turner, 1996:581). It could be the role of breadwinner, father, mother, employee or employer, and if a system is to enjoy stability and integration there must be some reciprocity of expectations between role partners. One could also have a role set, for example, an employee, husband, brother, friend or father. Performance of these roles is meant to contribute to the homeostasis of a family, work environment and community. Non-performance has detrimental effects on a system.

In the DSM iv TR (2000) alcohol abuse is described as recurrent alcohol use which results in failure to fulfil major role obligations at work, school or home, and continued alcohol use despite persistent or recurrent social or interpersonal problems. Pillari and Newsome (1998:16) are of the opinion that all family members play different roles in the family and, depending on the needs and desires of the family, these different roles are meant to fit into the family system. Role performance is affected when one abuses alcohol. Gans (2003:1) emphasises that alcohol abuse is a pattern of drinking that is accompanied by failure to fulfil major work, school or home responsibilities. A binge drinker whose drinking is out of control could fail to perform roles and responsibilities, and this could then affect family relations, work or school socially, psychologically or financially.

\section{Constructivism as a postmodern perspective}

The individual cannot be separated from his or her interactions with others (Poulin, 2005:26). Poulin notes that postmodernism highlights the importance of clients' subjective perceptions of their experiences, which are shaped by culture and social experiences. It places clients in the role of experts about their life experiences and potential solutions that can be reached through the process of interaction with a social worker. Constructivism as a postmodernism perspective is therefore relevant in understanding the effects of binge drinking on social support networks in that the members of networks could explain the causes and effects of binge drinking on their lives.

Saleebey (2006:10) identified six principles of a strengths-based perspective and one of them has to do with an acknowledgement that every individual, group, family and community has strengths, regardless of the situation; their assets, resources, wisdom and 
knowledge should be ascertained. These views are in line with postmodernism thinking that people have constructed their subjective reality, which could be seen or used as their strength when tackling the challenges. The strengths perspective proceeds from the premise that the micro and macro interventions would then be relevant to address the challenges.

The theoretical perspectives have as their basis that when one sub-system is affected, the others get affected as well. Binge drinking, for example, makes it difficult to perform roles that should benefit the network. The sub-system would then explain how they view social support and binge drinking.

\section{THE CONCEPTS}

In this section the concepts of social support, social support networks and social network analysis are analysed and explained in the context of the social and economic effects of binge drinking.

\section{Binge drinking}

Binge drinking has been described as excessive, immoderate, or heavy drinking in a single drinking session, over a short period and within a number of days or weeks (Mokdad et al., 2007:303; Naimi, Brewer, Miller, Okoro \& Mehrotra, 2007:188; Plant \& Plant, 2006:ix; Szmigin, Griffin, Mistral, Bengry-Howell, Weale \& Hackley, 2007:2; Wechsler \& Nelson, 2001:287).

\section{Social support}

Compton et al. (2005:256) and Seed (1990:30) describe social support using different terminology but focusing on common characteristics such as a positive interaction or helpful behaviour provided to a person in need of support or entitled to it. This has a connotation that social support is a general and directly beneficial quality of relationships. Tracy and Whittaker (1990:462) refer to social support as the many different ways in which people render assistance to one another.

As an individual characteristic, it is the individual who influences the size and composition of the social network and hence its capacity to provide support, and who seeks support, who does or does not accept it, who evaluates it and who integrates this evaluation into a relatively enduring and comprehensive cognitive-emotional representation of the social world. As a characteristic of the social environment, social support may denote behaviour regarded as supportive because of its obvious helping or comforting nature. Social support may refer to a particular attitude of members of the social network, whether expressed in specific behaviours, nonverbal clues or otherwise. This is viewed as their subjective reality which has meaning for recipients (Veiel \& Baumann, 1992:4).

Social support is viewed as support accessible to an individual through social ties, which are the networks, to other individuals. Hupcey (1998:1232) refers to Vaux's argument that social support encompasses social networks, perceived support and supportive behaviours. This view supports the fact that people are interrelated and interdependent and therefore are inseparable and have expectations of one another. If one person is 
affected, others get affected as well. These ties determine the type and exchange of support between the role players. One could make an assumption that excessive drinking could cause an imbalance in any system or network because of the interrelatedness and interdependence of the sub-systems. Failure to perform roles and expectations that others have about the support they should get from others could have negative effects for the systems or sub-systems.

Barker (2003:357) states that social support is "vital for human survival and development. It includes formal and informal activities as well as relationships that provide for the needs of humans in their attempts to live in society. These needs include a network of other individuals and groups who offer encouragement, access, role models and social identity". Social support is therefore expected from others, and provided by role players for significant others who are part of the social environment. It is provided to satisfy needs with a view to enhance social functioning.

According to Veiel and Baumann (1992:2), social support is defined "as an abstract characteristic of persons, behaviours, relationships or social systems". Social support can represent a characteristic of the recipient, of his/her environment, or of a social system including both the recipient and the environment. The environment could represent different social networks such as family, friends, kin, co-workers or the community. This description is supported by Seed (1990:37), who emphasises that network features refer to the specifics of an individual network, that is, people, places and activities in ones' environment.

Having examined the theoretical descriptions of social support, four themes as identified by (Hupcey, 1998:1232) are used to further unpack the notion of social support. These themes are types of support provided, recipient perception, reciprocal support and intentions or behaviours of the provider of support. A discussion of these four themes follows.

\section{Types of support}

Collins et al. (in Reis \& Rusbult, 2004:36) describe four broad types of support, namely emotional support, (expressions of caring, esteem, concern, caring, love and trust by family and friends), informational support (advice, suggestions or guidance that assist a person to respond to personal or situational demands), instrumental support (tangible goods such as money or assistance with tasks and other explicit interventions on the person's behalf) and appraisal support (which involves transmission of information in the form of affirmation, feedback and social comparison and is often evaluative).

One would have an expectation of receiving some kind of support from others and also provide it to others. The type of support that is provided and/or expected is also determined by a member's role and status in the network. These types of support are expected by members of the networks and failure to receive them can affect others negatively. Alcohol abuse makes it difficult to provide support that is expected. 
The social networks are therefore critical to provide the different types of support that are needed by others in the social environment. Survival of systems or networks depends on provision of all types of support.

\section{Recipient perception}

In defining social support a distinction can be made between the quality of support perceived and provided. The recipients' positive perception of the support provided, information and feedback would maximise positive effects. The individual needs to believe that his or her needs are fulfilled. Social support is the extent to which an individual believes that his/her needs for support, information and feedback are fulfilled. The support expected and provided should match; otherwise it will serve no purpose as the need would remain unsatisfied (Hupcey, 1998:1234).

She further states that not all social support is perceived as positive. The provider may provide support that is intended to be positive, but may be perceived negatively by the recipient. The recipient may perceive support as negative if there is interpersonal conflict that makes the recipient not accept the support provided. If a person who is a provider is abusing alcohol, even if he/she provides support, it may be viewed negatively because of the effect alcohol abuse has on the interpersonal relationships.

There are varied reasons for providing support. One important reason is that it is a social obligation or role stemming from one's status. Hupcey (1998:1233) states that in terms of social obligation an individual may feel required to provide support. If it is not provided willingly, the recipient may not feel positively about the support received.

It is deduced that the type of support provided should satisfy the recipient because it is congruent with the requirements or needs of the situation. Providers need to be responsive to changing needs as well. It is acknowledged that perceptions are subjective, but are nevertheless influential in determining the satisfaction with support given.

\section{Reciprocal support}

Reciprocal support entails an exchange of resources between recipient and provider (Hupcey, 1998:1232). The actual giving, receiving and exchanging of support is commonly referred to as the function of social support. The support that is not reciprocated may be considered negative support. A person could perceive that he/she is providing more support than he/she receives. It becomes a problem if there is a nonreciprocal network, because one could feel unappreciated. The person could also receive more support than what he/she provides. For example, a father who fails to support the family may still expect them to provide for him.

Collins et al. (in Reis \& Rusbult, 2004:36) agree that social support involves the exchange of social resources between individuals. They further argue that the definition of social support emphasises availability and receipt. Hupcey (1998:1232) states that social support is information leading a person to believe that he/she is cared for and loved, esteemed and valued and that he/she belongs to a network of communication and mutual obligation. The assumption is that if a person receives social support, his wellbeing will be enhanced. The person who abuses alcohol may not be in a position to 
provide the needed support, even if others support him in one way or the other. The view is supported by Tracy and Whittaker (1990:462), who note that not all networks are socially supportive, nor do they always reinforce positive social relationships.

\section{Intentions or behaviours of the provider of support}

Hupcey (1998:1234) states that the intentions or behaviours of the provider of support determine the satisfaction or dissatisfaction, or survival, functioning or dysfunctioning of a system. The provider would provide social support not as an obligation, but with an understanding that it is his/her responsibility. In that case it will be properly received and appreciated. If the behaviour of the person who is supposed to provide support is not acceptable, it might not be appreciated. Of importance is that the behaviour of the provider contributes to the normal functioning of a system.

To summarise, the categories of social support as outlined by Hupcey (1998:1232) namely type of support, recipient's perception, reciprocal support, and intentions or behaviours of the provider of support - are used to understand the support provided and received. The type of support that one gets from the network, whether it be material, emotional or social support, could enhance cohesion and improve and maintain the quality of relationships, because support networks will be satisfied now that their needs are met. The recipient's perception of the provided support is also critical; it is indicative of concern and commitment in the family or any system clearly showing the intention or behaviour of the provider to provide the resources needed. Support between the recipient and the provider should be reciprocal. That would also encourage expressiveness about needs, wishes or feelings, and this kind of environment would reduce conflict in a system.

Parents who abuse alcohol are often unable to provide their children with adequate care and support. Abuse of alcohol contributes to their spending time away from home when visiting drinking venues. Their role as parents is affected by alcohol abuse in many ways. Children are more likely to suffer from physical, mental or emotional problems because of lack of social support.

It is within this context that the article attempts to understand how binge drinking affects support networks.

\section{Social support networks/systems}

While social support describes specific functions of a network, social network describes the structure of the social relationships and quantity of a set of interconnected relationships (Tracy \& Whittaker, 1990:462; Veiel \& Baumann, 1992:36). It is described as a unit of social structure that represents people's patterns of living, includes all of an individual's social contacts and ties, or an individual's interaction with other persons and their relationships and connections (Bopape, 1993:8; Seed, 1990:30; Veiel \& Baumann, 1992:34).

Veiel and Baumann (1992:36) argue that to define a person's support network, one must examine a person's potential or actual supporters. These are also defined as "network resources", which are the part of a social network to which the person routinely turns to 
or would turn to for support and help. They further cite Moos, who refers to a supportive climate or environment as the quality of social relationships and systems: the family, the working place, or groups (such as drinking networks) and these are often defined by a high degree of interpersonal cohesion, involvement, expressiveness and a low degree of conflict. Cohesion means the degree of mutual help and support in that system. One could relate this to a family of a binge drinker to determine the help and support he gives or fails to give because of misuse of alcohol. Involvement characterises the degree of concern and commitment in the system. It goes with how one perceives his family and shows concern by putting them first before binge drinking. Expressiveness refers to the degree of mutual encouragement for an open expression of wishes, feelings and needs. Family members or friends could express their wishes on how the relationships should be, or their needs that have to be provided by an actor of a particular role. Conflict means the degree of stressful interactions and aggressive arguments. A balanced family or organisations where members are involved and free to express their views has a greater chance of being cohesive.

These definitions and explanations indicate that networks are structured, they are connections of individuals linked to their society primarily through relations with other individuals (with kin, friends and co-workers), and they provide support in one way or the other. Social support is provided by two different types of social support networks, namely formal and informal. The quality of the social support can be evaluated in terms of the degree of cohesion, involvement, expressiveness and conflict in the family system.

\section{Family system as a social support network}

In order to understand the type of support provided, how it is perceived, the behaviour of the provider and whether there is an exchange of resources, it is important to analyse the family as a system. Pillari and Newsome (1998:35) identified a family as made up of sub-systems, namely the members who can be divided into siblings and parental subsystems. There are implicit and explicit rules that govern roles, power and authority, and these are related to expectations. The family provides information about different forms or channels of communication that are useful for network analysis.

According to Maguire (1991:98), a healthy family structure meets the new and developing needs of infants and children, provides feedback and responds appropriately to their needs. The family also serves as protection against detrimental forces in the environment. It is through a family that a child learns to learn. It is within a family system that one first learns how to make linkages, connections or bonds with others. Successful bonding based on open and accurate communication leads to strong social support systems. Of importance is that the capacity to develop these systems in later life is invariably begun in the family system.

Children also model their parents' behaviour and learn how to develop social support systems and relationships by imitating or reacting to parental behaviour. Parents who are actively engaged with other adults in appropriate community, social cultural or religious activities model the same healthy interactions for their children. The family provides 
socialisation for children. Families are responsible for the identification that shapes values, attitudes and social skills. It is also important to note that an individual is a product of his or her family because of socialisation, and that the family and its dynamics are a product of the community, culture and society within which it is based (Maguire, 1991:99).

The issue is whether a person who misuses alcohol or engages in heavy episodic drinking would be available to provide this guidance or bonding to a developing child. The drinking affects the balance or homeostasis of the family system, as well as the growth and healthy development of subsystems. Parental drinking is correlated with child abuse and impacts on a child's environment in many social, psychological and economic ways (Gmel \& Rehm in WHO, 2004:60). In systems theory a system is a whole with interrelated and interdependent parts. For instance, if a binge drinker loses his/her job, or dies in an accident, the children and spouse are affected.

The families would also adopt patterns of coping because of their needs and exposure to some behaviours. Children of binge drinkers would be forced to choose between parents because of the negative behaviours displayed by the drinker or the bad financial situation they are in. They would develop coping skills that exclude the drinker. Maguire (1991:102) says children feel that they must choose between parents especially if one is abusing alcohol and not able to provide emotional, material or instrumental support, and indeed, when the parents have become alienated and polarised, the children are often forced to make that choice. The spouses also suffer because of the partner who is a binge drinker. Failure to provide any form of support could affect the spouse negatively and the consequences could be detrimental for the individuals involved as well as the system. The situation is aggravated when both parents abuse alcohol. Children become more exposed to child abuse and neglect.

The spouses are affected by binge drinking in many ways, including lack of emotional, material or instrumental support from spouses. This could lead to depression, anger, anxiety or divorce. At times spouses and other family members (social support networks) have to attend Al-Anon group sessions to deal with the negative effects of alcohol that are caused by their partners or parents who abuse alcohol. The WHO (2004:61) states that the effects of men's drinking has risks for their spouses such as violence, HIV infection and an increased burden in their role of economic providers.

The family system is affected by the degree of support or lack of it in the neighbourhood, or work environment. The negative behaviour displayed by drinkers does affect them as individuals and their families as well. This usually starts in the second stage of alcohol use, when a drinker starts to experiment with alcohol and binge drinking is noticed occasionally. It causes concern for the family because bingeing is heavy, risky drinking. The challenge is when the drinker moves to the third stage of high risk, which refers to excessive drinking. This stage is characterised by a high frequency of alcohol abuse, serious enough to be dangerous for the drinker and those around him or her (Caron Texas Professional, 2013). 


\section{The value of support networks}

Cunningham, Van Mierlo and Fournier (2008:193), in their study of an online support group for problem drinkers undertaken in Canada, have identified that social support networks can help people resolve their problem drinking. Groh, Jason and Keys (2008) support this view in their study "Social network variables in alcoholics anonymous: a literature review". They reviewed 24 papers to examine the relationship between AA and social network variables. They considered various types of support, namely structural, functional, general and alcohol-specific support, and recovery helping. The review found that AA involvement is related to a variety of positive qualitative and quantitative changes in social support networks. Of relevance for this study is the fact that social support networks play a major role in the life of the drinker, and the drinker has a major impact on social support networks.

The importance of social support networks is also demonstrated by Olagnero, Meo and Corcoran (2005:53) in their study of social support networks in impoverished European neighbourhoods. Of significance in this study is that social support networks are reinforced or further weakened by factors such as economic hardship, unemployment and neighbourhood dereliction. The significance of support networks is highlighted by Gass, Weitzen, Clark and Dizon (2007:501) in their study on social support systems for women with breast cancer that their pervasive effects impact on the patient, her spouse, children, extended family and entire social structure. Respondents were asked to describe what primary support meant for them; $52 \%$ characterised it as emotional and $23 \%$ defined it as a combination of roles, usually emotional and structural in nature. Less than $10 \%$ defined primary support as purely structural or informational in nature. The point is that social support networks have a role to play and in return are affected by situations, negative or positive, that others are exposed to. Binge drinking fits this scenario because of its negative effects on the networks that have expectations in terms of provision of material aid, emotional support, socialisation or even information giving.

Maguire (1991:xv) is of the view that social support provides five resources, namely a sense of self, encouragement and positive feedback, protection against stress, knowledge, skills and resources, and socialisation opportunities. Support systems play a critical role in maintaining the psychological integrity of the individual over time. This view is supported by the study on adolescent peer networks as a context for social and emotional support that was undertaken by Staton-Salazar, Spina and Urso (2005:379) in California using a combination of qualitative and quantitative methodologies, in which participating adolescents found in their friends the support necessary to withstand emotionally challenging circumstances and to cope in effective ways.

Borgatti (2005a:2) is of the view that social support networks provide social and economic support at varying levels. This view is echoed by Strathdee (2005:1), who states that social networks are used to assist young people by facilitating transition into work. He argues that the presence of familial and community-based social networks that are deeply rooted in the social infrastructure prepare the young people for integration into the labour market. Familial networks also play an important role in transmitting 
skills between generations. This supports the view that networks contribute to development of their members.

Compton et al. (2005:267) identify the benefits of informal support as physical and psychological wellbeing, satisfying of social and emotional needs, socialisation, recreation, protection against loneliness and isolation, and acting as a buffer against stress and hardships. It also promotes mental health, which refers to one's perception of the quality of one's life and functioning, or role performance relative to one's capabilities. According to Maguire (1991:98), the foundation for mental health is invariably laid in the family. Social support networks enhance personal wellbeing, life satisfaction and quality of life, and they also contribute to individual feelings of selfesteem, connectedness or belonging. The significance of social support is that it has a protective or buffering effect on an individual's health or mental health. Social support may also reduce delinquency by providing a conducive environment in which children feel supported and loved. The essential element of a family is respect for the needs of all members. The Victorian Health Promotion Foundation (2005:2) make reference to a study of 2000 people in Finland found that social support strengthened mental health in all respondents. Kawachi and Berkman (2001:458) are also of the view that social networks and social ties have a beneficial effect on mental health outcomes, including stress reactions and psychological wellbeing.

Fu, Anderson, Courtney and Hu (2007:285) undertook a study on the relationship between culture, attitude, social networks and quality of life in mid-life Australian and Taiwanese citizens. The results show that there is a significant relationship. The research found that good social support networks and a healthy optimistic disposition may significantly enhance men and women's quality of life. They further state that social networks can be defined as the subjective feeling of belonging, of being accepted, loved, wanted, esteemed, valued and needed for oneself (Fu et al., 2007:286). On the other hand, a study by Litt and Mallon (2003:3) has shown that social networks that reinforces drug use lead to more drug use, while networks that reinforce a clean and sober lifestyle leads to higher drug abstinence. These networks play an important role in the lives of people. Litt and Mallon (2003) further refer to a study by Gordon and Zrull (1991) indicating social network data on 156 alcoholics show that active support of nondrinking friends and co-workers was the most influential factor in recovery. Most predictive of poor outcomes was encouragement of drinking by co-workers, some of whom were co-drinkers.

It is concluded that social support networks provide care and assistance because they are a resource that one needs in life to contribute to wellbeing. Insight into the value or significance of social networks in peoples' lives is critical to be able to understand how a person who abuses alcohol affects those networks that expect support from him or her. Social support is closely related to the concept of a social network, or the ties to family and significant others. Social support can therefore be provided spontaneously through natural helping networks of family and friends, or can be mobilised through professional intervention. 


\section{Social network analysis}

The descriptions and definitions of social support networks indicate how important it is to analyse how a network or any matter pertaining to it functions. This would help to clarify the structure, the linkages, the lines of communication and the roles. Freeman (2004:2) states that the study of interactions among social actors is called social network analysis. He is of the view that the social network approach is grounded in the intuitive notion that the patterning of social ties in which actors are embedded has important consequences for those actors. Network analysts, then, seek to uncover various kinds of patterns. They try to determine the conditions under which those patterns arise and to discover their consequences. This approach is supported by Tracy and Whittaker (1990:462), who state that analysis of the social network could assess various types of supportive exchanges, and describes the existence or quality of relationships, determines the frequency of specific supportive events, ascertains perceived availability, or evaluates adequacy of support. This fits well the description of social support provided by Hupcey.

Social network analysis is more general and can be used to analyse any network. Everett and Borgatti (2005:31) refer to ego networks (Figure 1), which represent a network of a single actor (ego 1) together with actors (2-12) they are connected to (alters) and all the links among those actors. The ego networks are used to study social support.

FIGURE 1

\section{THE KEY PLAYER PROBLEM (KPP) - THE CENTRALITY APPROACH}

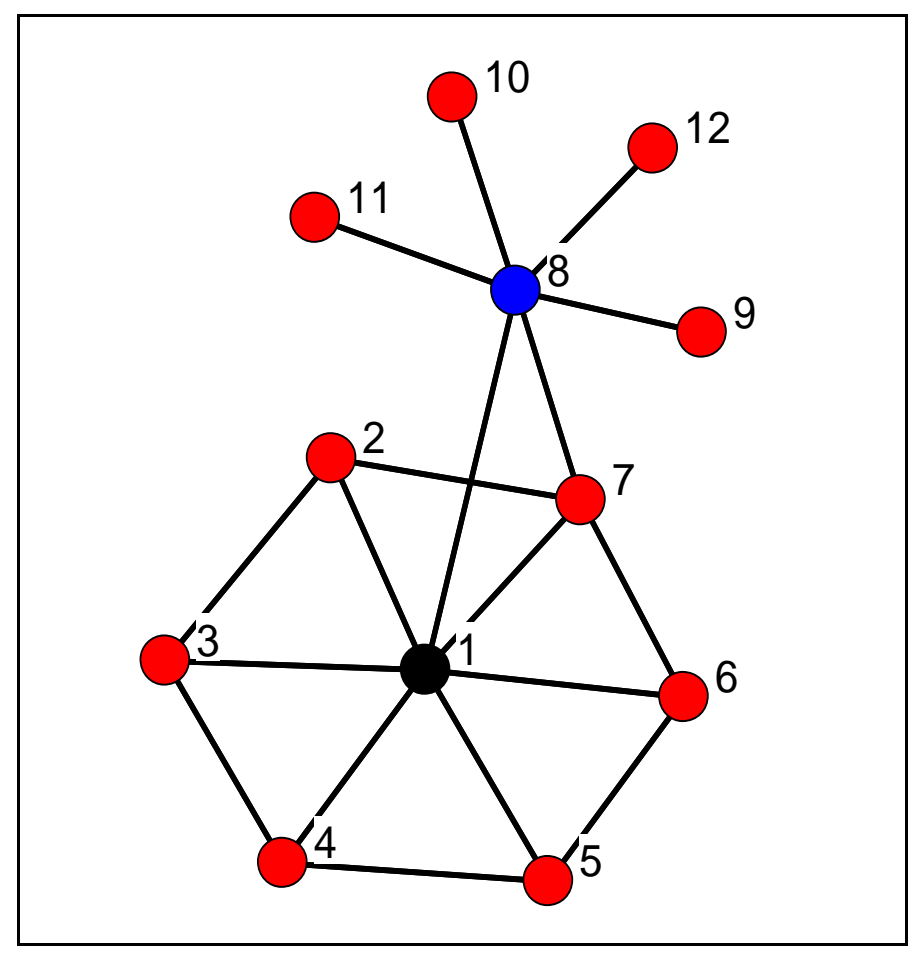

Source: (Borgatti (2005b:2) - (Permission granted for use)

Maguire (1991:46) is of the opinion that, based on analysis of the structure of networks, their interactional patterns and functions of intimate, socially supportive relationships strategies can be developed to strengthen networks where they exist, develop new ones 
when they are needed, and leave them alone when they are working. Social network analysis is used to establish more precisely the specific purposes and functions of different types of networks or network configurations, and using that information can assist in assessment and intervention.

In social work an eco-map, also called a socio-gram, is used to analyse networks. It is a visual assessment tool depicting the relationships of family and its network (Hartman, 1995:111) and portraying the ecological context in which people live, because it provides a diagrammatic representation of a person's world (Hartman \& Wickley cited in Cournoyer, 2000:40). It is a drawing of the client or client family in its social environment that indicates the main systems which form part of the person's life and the nature of the relations with other systems, and it also provides an overview of the family in their situation, giving a picture of important nourishing or conflict-charged links. It is then used to analyse the family in order to understand how it functions. It is in this analysis that one can depict the responses of members of a support network regarding the support that is provided or not.

The eco-map could be used to achieve a holistic or ecological view of the client's family life and the nature of the family's relationships with groups, associations, organisations, other families and individuals. A major value of an eco-map is that it helps to show the environmental context from a systems and ecological perspective. Identifying the connections clarifies data on a family's environment; it highlights energy that flows into and out of the family. It also provides information on aspects such as network size, reciprocity of relationships and access to, or deprivation of, resources (Cournoyer, 2000:40).

Of importance is that it also identifies the energy-enhancing and energy-depleting relationships between members of a social system and the outside world; it also highlights social strengths and social deficiencies, and identifies conflict and compatibility that could be caused by excessive drinking. In that case it is a tool that one could use for social network analysis to understand system dynamics and, in this particular study, it would help in identifying the social and economic effects of binge drinking on support networks (Hartman, 1995:112). A study of families with binge drinkers as central figures would provide a picture of, for example, how the family is structured, its strengths and weaknesses, balance and available resources in the community.

Tracy and Whittaker (1990:462) acknowledge that the eco-map is an extremely useful method for portraying client-environment relationships, as well as for demonstrating the flow of energy into and from the family, and depicting nurturing as well as conflicted relationships. However, one disadvantage is its imprecise terms, which make it difficult to determine the exact nature of the relationships portrayed. Their view is that the ecomap provides a much more complete portrayal of structure than it does of function. They introduced a social network map (Figure 2) that identifies and visually displays network composition and membership. It attends to both structure and function. It is a tool for systematically gathering specific information on the size, composition, structure and 
functioning of a person's social support network. Their view is that social network mapping techniques are fully compatible with eco-map procedures, but they provide more detailed, anchored responses regarding the quality and functioning of social connections. The social network map is constructed for an individual and lists each person known to that individual.

FIGURE 2

SOCIAL NETWORK MAP

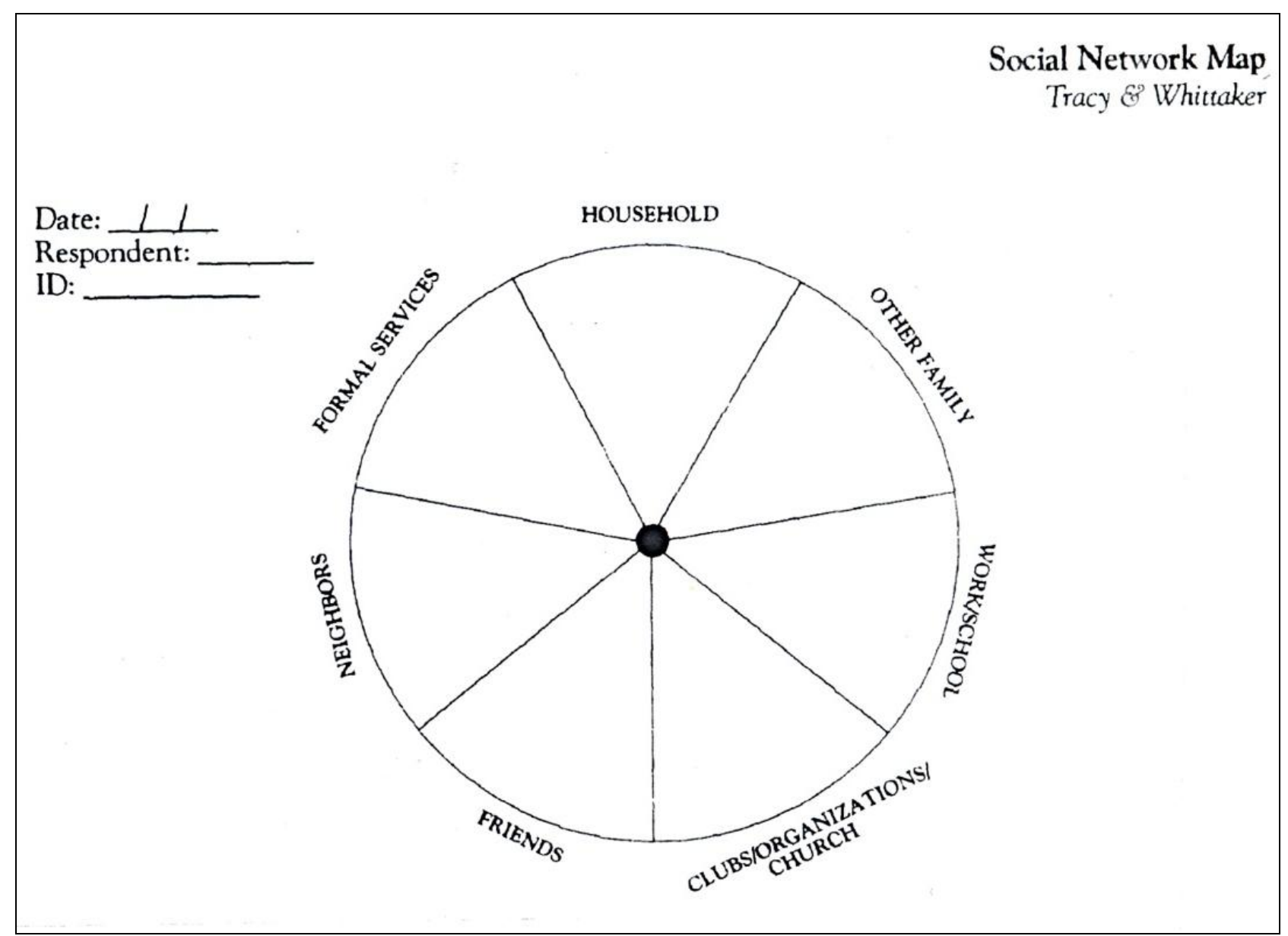

Source: Tracy and Whittaker (1990:463)

A grid is used with the social network map to record responses to supportive and nonsupportive functions of network relationships, for example, which network provided what type of support, what relationships were reciprocal, and what relationships were conflicted. Their view is that the network grid (Figure 3) is specific about network functions and the fact that relevant information about the target population can be directly collected. 
FIGURE 3

SOCIAL NETWORK GRID

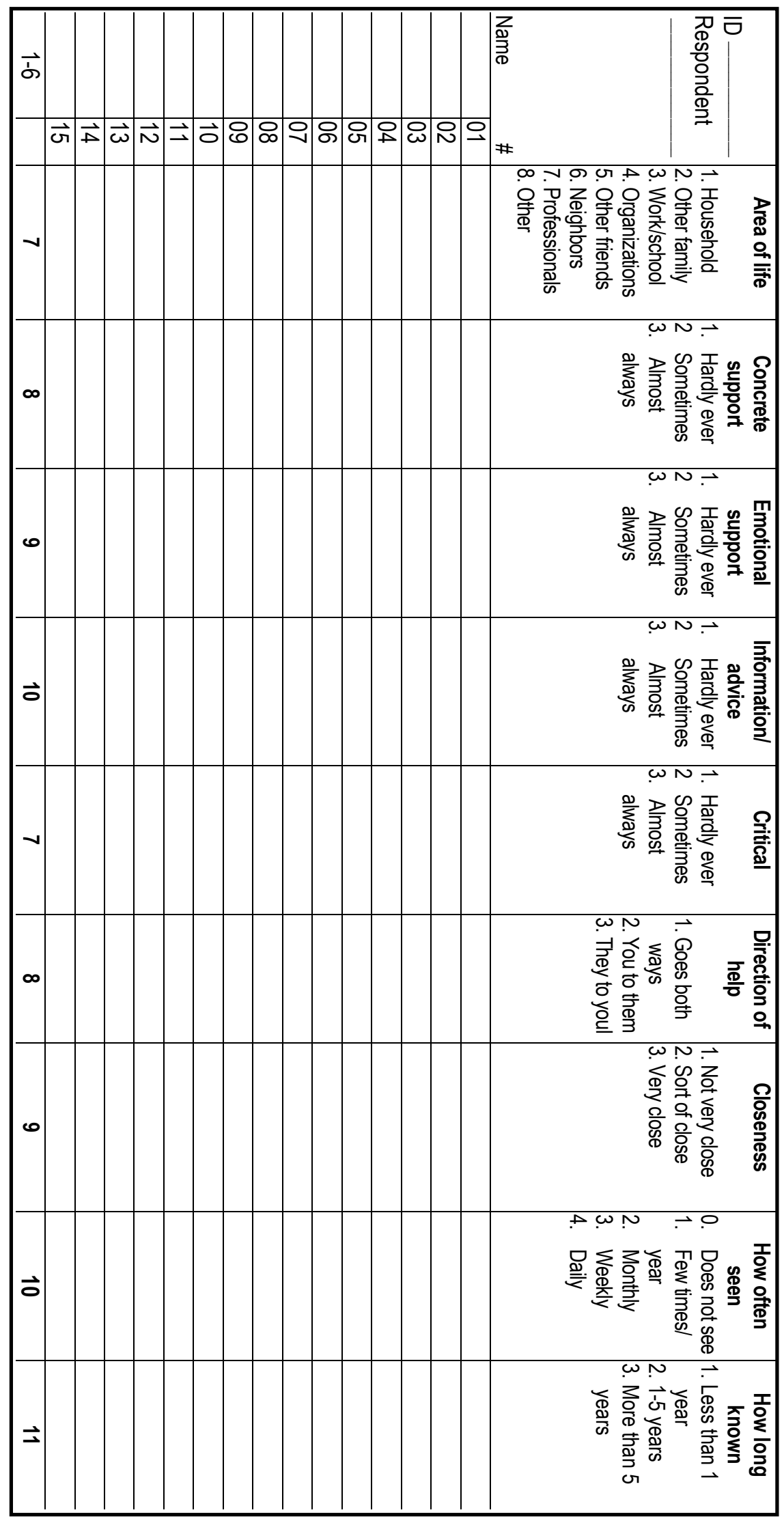


Morris (2003:1) states that a social network map is useful for people who experience special circumstances such as serious illness, disability, divorce or job loss. The person would make a list of needs and break them into categories that are meaningful to that person, focusing on instrumental, expressive and emotional needs as well as concrete practical tasks. A person then identifies the people who have helped with each of these needs and those one could ask for assistance with each need. One would then see if there are any holes (needs going unmet). It is important to then consider why this is happening. A pattern should be identified. It is also important to note the ways a person reciprocates by meeting the needs of the people in the social network.

The social network map and the grid are useful tools that could be used to get information to understand how binge drinking affects family members, work environment or friends. Tracy and Martin (2007:81) state that given the social nature of substance abuse, assessment of social networks is helpful in understanding addictions. This view was expressed in their study to document the role of children in the social networks of women in substance abuse treatment. Their argument is that there is an association between substance use patterns and women's relationships with significant others. Reference is made to the study by O'Dell, Turner and Weaver (1998) that found that drug-misusing women had very small social networks and received minimal support for sobriety from partners and parents.

An assumption is made that the binge drinker as a family member, a worker, a friend has connections with other systems and they do affect one another as they are interrelated and interdependent. There are interactions and transactions that take place among actors. Whittaker and Garbarino (1983:9) refer to this as the ecological niche of an individual and his or her immediate environment, and both affect and respond to each other. They further states that the individual's environment is multifaceted and multileveled.

\section{DISCUSSION AND CONCLUSION}

The concepts "social support" and "social network" are useful to understand the supportive environment of the binge drinker. In order to further understand the concepts of social support, social support networks and social support network analysis in relation to binge drinking, three supporting theoretical frameworks have been discussed to highlight the person-in-environment paradigm, social functioning and reality as described by participants.

Social support networks play an important role in the lives of individuals and others in their immediate environment. Wechsler and Nelson (2001:288) state that binge drinking is a good indicator of the problems binge drinkers produce for those around them. Failure to receive material or emotional support could lead to negative social or economic effects, especially if a binge drinker does not perform a role as expected. Role theory illustrates the importance of role performance and how it enhances a balance of a system, which could lead to cohesion that also promotes expression of their views because they are involved. It is a given, then, that for a system to be balanced, roles have to be performed, needs have to be satisfied and high-quality relationships should be maintained. This is possible if social support is provided by all actors. 
In order to enhance the social functioning of drinkers and their networks, social workers and other role players should perform a thorough social network analysis to understand the situation that informs the intervention.

It is concluded that social support networks are negatively affected by binge drinking. In order to address the problem of binge drinking, a detailed analysis of the social support networks is critical, because it assists in understanding how these networks are structured and how they function in their ecological world in terms of performance of roles, views about alcohol, and the provision of emotional, material and instrumental support, and how support is perceived and reciprocated. It then provides a detailed picture that leads to an understanding of the social and economic effects that are experienced by social support networks. A relevant comprehensive strategy should be informed by real-life situations and should be mindful of different dynamics of families and communities. Current strategies are to be evaluated to determine their effectiveness. When policies, frameworks or plans are developed, attention should be given to the characteristics, effects and consequences of alcohol use.

This information is critical and could contribute to the development of a relevant, integrated and coherent strategy to address alcohol use, misuse or abuse in South Africa.

\section{REFERENCES}

BARKER, R.L. 2003. The Social Work Dictionary $\left(5^{\text {th }}\right.$ ed). Baltimore: NASW Press.

BECKER, H.A. \& VANCLAY, F. 2003. The International Handbook of Social Impact Assessment: conceptual and methodological advances. Northampton, MA: Edward Elgar Publishing.

BOPAPE, M. 1993. Social networks and social support as a basis of community development in Lebowa. Pretoria: Human Sciences Research Council.

BORGATTI, S.P. 2005a. Social Support. UCINET 5 for Windows: software for social network analysis. Natick; MA: Analytic Technologies. [Online] Available: http://www.analytictech.com/networks/socsup.html. [Accessed: 22/08/2007].

BORGATTI, S.P. 2005b. The Key Player Problem (KPP) - the centrality approach. UCINET 5 for Windows: software for social network analysis. Natick; MA: Analytic Technologies. [Online] Available: http://www.analytictech.com/networks/socsup.html. [Accessed: 22/08/2007].

CARON TEXAS PROFESSIONAL. 2013. Seven stages of alcohol addiction. [Online] Available: www.carontexas.org/treatment programs. [Accessed: 17/02/2014].

COMPTON, B.R., GALAWAY, B. \& COURNOYER, B.R. 2005. Social work processes $\left(7^{\text {th }}\right.$ ed). Pacific Grove: Brooks/Cole. 
COURNOYER, B. 2000. The Social Work Skills Workbook. Pacific Grove: Wadsworth Publishing.

CUNNINGHAM, J.A., VAN MIERLO, T. \& FOURNIER, R. 2008. An online support group for problem drinkers: AlcoholHelpCenter.net. Patient Education and Counseling, 70(2):193-198.

DIAGNOSTIC AND STATISTICAL MANUAL OF MENTAL DISORDERS (DSM ivtr $2000\left(4^{\text {th }}\right.$ ed $)$. Washington, D.C: APA.

EVERETT, M. \& BORGATTI, S.P. 2005. Ego network betweenness. Social Networks, 27:31-38.

FREEMAN, L.N. 2004. The development of social network analysis: a study in the Sociology of Science. Cambridge: Empirical Press.

FU, S.K., ANDERSON, D., COURTNEY, M. \& HU, W. 2007. The relationship between culture, attitude, social networks and quality of life in midlife Australian and Taiwanese citizens. Maturitas, 58:285-295.

GANS, S. 2003. What is alcohol abuse? Alcohol - getting the facts. [Online] Available: About.com.Alcoholism. [Accessed: 04/02/2008].

GASS, J.S., WEITZEN, S., CLARK, M. \& DIZON, D.S. 2007. Defining social support systems for women with breast cancer. The American Journal of Surgery, 194:501-503.

GROH, D.R., JASON, L.A. \& KEYS, C.B. 2008. Social network variables in alcoholics anonymous: a literature review. Clinical Psychology Review, 28(3):430-450.

HARTMAN, A. 1995. Diagrammatic assessment of family relationships. Families in Society: The Journal of Contemporary Human Sciences, 76(2):111-112.

HULL, G.H. (Jr) \& MATHER, J. 2006. Understanding generalist practice with families. Belmont, CA: Brooks/Cole.

HUPCEY, J.E. 1998. Clarifying the social support theory - research linkage. Journal of Advanced Nursing, 27:1231-1241.

KAWACHI, I. \& BERKMAN, L.F. 2001. Social ties and mental health. Urban Health, 78(3):458-467.

LONG, D.D., TICE, C.J. \& MORRISON, J.D. 2006. Macro social work practice: a strengths perspective. Belmont, CA: Brooks/Cole. 
LITT, M.D. \& MALLON, S.D. 2003. The design of social support networks for offenders in outpatient drug treatment. Federal Probation, 67(2):15-21.

MAGUIRE, L. 1991. Social support systems in practice: a generalist approach. Silver Springs, MD: NASW Press.

MOKDAD, A.H., BREWER, R.D. \& WARNER, L. 2007. Binge drinking is a problem that cannot be ignored. American Journal of Preventive Medicine, 44:303-304.

MORRIS, D.H. 2003. Encouraging plus coaching: Mapping your social network. The Encourager Newsletter, 2. Date of access: 30 September 2009.

NAIMI, T.S., BREWER, R.D., MILLER, J.W., OKORO, C. \& MEHROTRA, C. 2007. What do binge drinkers drink? Implications for alcohol control policy. American Journal of Preventive Medicine, 33(3):188-193.

NORMAN, P., ARMITAGE, C.J. \& QUICKLEY, C. 2007. The theory of planned behaviour and binge drinking: Assessing the impact of binge drinking prototypes. Addictive Behaviors, 32(9):1753-1768.

O'DELL, K.J., TURNER, N.H. \& WEAVER, G.D. 1998. Women in recovery from drug misuse: an exploratory study of their social networks and social support. Substance Use and Misuse, 33(8):1721-1734.

OLAGNERO, M., MEO, A. \& CORCORAN, M. 2005. Social support networks in impoverished European neighbourhoods. European Societies, 7(1):53-79.

PARRY, C.D.H., PLÜDDEMAN, A., STEYN, K., BRADSHAW, B., NORMAN, R. \& LAUBSHER, R. 2005. Alcohol use in South Africa: findings from the first demographic and health survey. Journal of Studies in Alcohol, 66:91-97.

PLANT, M. \& PLANT, M. 2006. Binge Britain - alcohol and national response. London: Oxford University Press.

PILLARI, V. \& NEWSOME, M. (Jr). 1998. Human behavior in the social environment families, groups, organisations and communities. Pacific Grove: Brooks/Cole Publishing.

POULIN, J. 2005. Strengths-based generalist practice: a collaborative approach. $\left(2^{\text {nd }}\right.$ ed $)$. Belmont, CA: Brooks/Cole.

REIS, H.T. \& RUSBULT, C.E. 2004. Close relationships. New York: Psychology Press. 
SALEEBEY, D. 2006. The strength perspective in social work practice $\left(4^{\text {th }} \mathrm{ed}\right)$. Boston: Allyn and Bacon.

SEED, P. 1990. Introducing network analysis in social work. London: Jessica Kingsley Publishers.

SKWEYIYA, Z. 2005 Speech by the former Minister of Social Development - Ke Moja Rollout, Goldreef City, $11^{\text {th }}$ March.

STANTON-SALAZAR, SPINA, R.D. \& URSO, S. 2005. Adolescent peer networks as a context for social and emotional support. Youth \& Society, 36(4):379-417.

STRATHDEE, R. 2005. Social exclusion and the remaking of social networks. London: Athenaeum Press.

SZMIGIN, I., GRIFFIN, C., MISTRAL, W., BENGRY-HOWELL, A., WEALE, L. \& HACKLEY, C. 2007. Re-framing 'binge drinking' as calculated hedonism - Empirical evidence from the UK. International Journal of Drug Policy, 1-8.

TRACY, E.M. \& MARTIN, T.C. 2007. Children's roles in the social networks of women in substance abuse treatment. Journal of Substance Abuse, 32:81-88.

TRACY, E.M. \& WHITTAKER, J.K. 1990. The Social Network Map: assessing social support in clinical practice. Families in Society: The Journal of Contemporary Human Services, 8:461-470.

TURNER, F.J. 1996: Social work treatment: interlocking theoretical approaches. New York: Free Press.

VEIEL, H.O.F. \& BAUMANN, U. 1992. The meaning and measurement of social support. New York: Hemisphere Publishing Corporation.

VICTORIAN HEALTH PROMOTION FOUNDATION. 2005. Social inclusion as a determinant of mental health and wellbeing. Research summary. [Online] Available: www.vichealth.vic.gov.au/MHWU/. [Accessed: 04/2009].

WECHSLER, H. \& NELSON, T.F. 2001. College student: what's five drinks. Psychology of Addictive Behaviors, 15(4):287-291.

WELLMAN, B. \& BERKOWITZ, S.D. 1988. Social structures: a network approach. New York: Cambridge University Press.

WHITTAKER, J.K. \& GARBARINO, J. 1983. Social support networks: informal helping in the human services. New York: Aldine. 
WORLD HEALTH ORGANISATION (WHO). 2000. Global status report on alcohol. Geneva, Switzerland.

WORLD HEALTH ORGANISATION (WHO). 2004. Global status report on alcohol. Geneva, Switzerland.

WORLD HEALTH ORGANISATION (WHO). 2011. Global status report on alcohol. Geneva, Switzerland.

Dr Marilyn Setlalentoa, School of Social Sciences, North-West University, Mafikeng Campus, South Africa; Prof Elma Ryke and Prof Herman Strydom School of Psychosocial Behavioural Sciences (Social Work) Potchefstroom Campus, South Africa. 